\title{
THE STRATEGIES OF UNITED NATIONS DEVELOPMENT PROGRAMME (UNDP) WITH GLOBAL ENVIRONMENTAL FACILITY (GEF) TO PROMOTE SUSTAINABLE LAND MANAGEMENT
}

\author{
Recindy Gilang Melati \\ President University, Indonesia \\ Email: ercndygm@gmail.com
}

\begin{abstract}
International organizations playing a important role in overcoming various issues in the World. Based on this case UNDP is determined to assist every country in carrying out sustainable development, in this case Environmental Issues have a greater impact on the continuity of human security. This happens based on the basis of 2 things, which are the act of human activity itself or from natural changes. One of the environmental issues that are often faced in every countries is land degradation, this environmental issue is also experienced by Kenya as a country from the East African continent where many of the people depend on livelihoods from the agricultural sector especially Argo-Pastoral. The cases of land degradation with the variations state of the land type give socio-economic impacts for the people and communities whose livelihoods depend on the land. The existence of an international organization which is UNDP as a means to help environmental issue in Kenya land degradation by applying a sustainable land management system. In this study the author will conduct a study with the aim of analyzing the strategy of the International Organization, which UNDP in applying a sustainable land management system in cases of land degradation so that it can provide results for the production system of the Argo-Pastoral. This research is taken from the UNDP and GEF projects that have been ongoing from 2011-2016 with the name Mainstreaming Sustainable Land Management in Argo-Pastoral Production System of Kenya.
\end{abstract}

Keywords: international organization; sustainable land management; argo-pastoral production system; land degradation.

Received: 2021-12-20; Accepted: 2022-01-05; Published: 2022-01-15

\section{Introduction}

Environmental Issues were become a global issues based on the United Nations Conference on Human Environment on 1972, in Stockholm. Since the issues getting huge, Environmental Issues have been bring up to the top of the level in scale of National and International Development Agendas by demonstrated at 1992's United Nations Conference on Environment and Development (UNCED) in Rio de Janeiro (K.Mutiso, 1994).

$\begin{array}{ll}\text { How to cite: } & \text { Melati. R.G (2022) The Strategies of United Nations Development Programme (UNDP) With Global } \\ & \text { Environmental Facility (GEF) To Promote Sustainable Land Management. Syntax Literate: Jurnal Ilmiah } \\ & \text { Indonesia, 7(1). http://dx.doi.org/10.36418/ Syntax-Literate.v7i1.5690 } \\ \text { E-ISSN: } & 2548-1398 \\ \text { Published by: } & \text { Ridwan Institute }\end{array}$


The interlinkages between environmental and human security which identified "ecological damage as a new risk for stability" According to Duffield and Waddell Security is no longer matter of a states, meanwhile is about the individual or what called as Human security, it leads to security issues in the daily lives of every individual (Duffield \& Waddell, 2006).

Environmental issues continuing become a major concern for all countries, and Kenya has its own environmental challenges, such as land degradation it happened by Resulting from a process or combination of processes arising from land use or human activities (Bartelmus, 2013).

In fact, there are a total of 72 regions in Kenya conditions which 11 are classified as arid, 19 as semi-arid, and another 6 as arid and semi-arid with high annual rainfall but with a total area of approximately it is 467,200 square kilometer, thus cover $80 \%$ of the land area and are characterized by a number of interrelated factors, including a generally hot and dry climate, population growth and agricultural interference with the surrounding land (Castrén et al., 2010). Kenyan who is lived in the area about $60 \%$ of ASAL residents live below the poverty line which (less than $\$ 1$ a day) and suffer from land degradation, desertification and drought. Although the majority of the population is pastoralists and agronomists, agricultural communities have migrated from highpotential and mid-level areas to dry land, which has impacted land use, subsistence farming and lifestyle changes (Busch et al., 2010).

According to the Population and Housing Census data, Kenya had a population of 38.6 million in 2009, with a CAGR of $3.0 \%$. The majority of Kenyans $(67.2 \%)$ live in rural areas, $32.5 \%$ live in urban areas, and $75 \%$ of Kenya's population is under the age of 30 (Gok \& Aytas, 2009) Most of Kenya's life is dependent on land, and the agricultural sector continues to play an important role as the core of Kenya's economy, contributing $26 \%$ of GDP and $27 \%$ of GDP indirectly through connections. With other fields. Kenya's agriculture is also large and complex, with many government, state, nongovernmental and private sectors. Kenya's main agricultural products include tea, coffee, horticulture, corn, wheat, sugarcane, dairy, beef, pork and poultry, egg (Plaizier, 1993).

More than $80 \%$ of Kenya's land area is in cattle breeding, farmland and surrounding agricultural areas, which are generally the areas with the most food insecurity. The section below provides general information about this livelihood group according to (The Impact of Rising Food Prices on Disparate Livelihood Groups in Kenya, 2008).

Pastoral livelihood is one of the most food insecure regions of the country, mainly in Turkana, Marsabit and Moyale, Samburu, Mandera, Vajr, Garissa, Isiolo, Ijara, Tana River, Narok and Kajiado regions. The region receives very variable rainfall due to frequent droughts and floods. Drought periods have been longer and more frequent over the past 10 to 15 years. Annual rainfall is very low and ranges from 250 to $400 \mathrm{~mm}$.

Agro-pastoral livelihoods It is found in many parts of the country, including the counties of Baringo, Koibatek, West Pokot, Payne, Laikipia, Samburu, Trans Mara, 
Narok, Turkana, Isiolo, and Kajiado. Argo Pastoral have several similarities to pastoral Crop production is a viable option in livestock areas, but subject to rainfall fluctuations ranging from 300 to $600 \mathrm{~mm}$ per year.

The marginal agricultural livelihood is a predominant feature in the southeastern areas and coastal lowlands of the country, including Tharaka, Mbeere, Meru North, Makueni, Machakos, Mwingi, and Kitui counties in the southeast, and Taita Taveta, Malindi, Kilifi, Lamu, and Kwale counties in coastal areas. However, agricultural production is marginal due to low use of inputs and low and poorly distributed rainfall, with drought tending to occur during the March-May long rains seasons.

That is how situation impacted the Agricultural Productivity system that in addition according to (Brabham, 2008) it massed up the livestock production and involved some form of crop cultivation, and it goes to the economic impact of land degradation, according to (Moschella, 2010) estimated that land degradation has a large economic cost in Kenya of around 390 million USD or around 3\% of GDP per year. These costs are related to the decline in soil quality as a result of unsustainable agricultural practices, the impact of climate change, soil erosion, pollution and toxicity from agro-chemicals and alien and invasive species such as Ipomea kituiensils, Prosopis juliflora, and water hyacinth.

However, The growth of agricultural output in Kenya is constrained by many challenges including soil erosion, low productivity, agro-loss, and soil nutrient depletion, thus making the food crop productivity growth in the country has over the last decades failed to exceed population growth, and it become the causes of Food Insecurity (Mulinge \& Mueller, 1998).

In another side there are many national policies and sectoral policies that Kenya government has been create to support SLM implementation and for the agriculture sector itself has 117 policies and jurisdictions related to SLM that has spread into across sector and national policies. However, some of these laws contradict each other, while others are invalid or redundant. Fragmentation of policy creates many information gaps, and the most relevant policies and laws affecting SLM include the ASAL on draft policy, the Forest Act, the Environmental Management Coordination Act (EMCA), the Water Act, and the Poverty Reduction Strategy Document (PRSP), Northern Regional Environmental Plan (NPEP), Kenya's National Development Plan and Livestock Development Plan (KLDP) (Mcsweeney, New, Lizcano, \& Lu, 2010).

Kenya vision 2030 is the brand new improvement blueprint for the country protecting the length 2008 to 2030 primarily based on three "pillars" - economic, social and political. It objectives at making Kenya a "middle earnings country presenting excessive great lifestyles for all its citizens through the year 2030". The vision has been evolved through an all inclusive stakeholder consultative technique in all elements of the country (Yildiz, 2007).

Based totally on Kenya imaginative and prescient 2030 in Medium time period Plan on 2008-2012 the authorities of Kenya is already examine the scenario and create 
the help assignment and applications to obtain the outcome relate to the 3 pillars and Agriculture is covered on economic Pillar.

Agriculture is one of the essential sectors within the country with notable boom capability, accounting for around 24 percentage of GDP, 75 percentage of commercial raw substances and 60 percent of export profits. The world is recognized as one of the principal livelihoods of rural groups, with an anticipated three. 8 million Kenyans employed at once in agriculture, farm animals production and fisheries at the same time as another 4.5 million are hired in casual sector sports off-farm (First Medium Term Plan 2008-2012, p. 77).

Livestock manufacturing is one of the principal sports on this sector. Furthermore, it is practiced in all parts of Kenya either below good sized pastoral systems in arid and semiarid areas (ASAL) or beneath in depth, livestock and smallholder structures. farm animals and commercial systems have traditionally contributed to deliver of beef and meat inventory is small, farm animals production in ASAL is nearly $90 \%$ of employment possibilities and almost ninety five $\%$ of own family profits. It additionally debts for about forty\% of Agricultural GDP and approximately 30\% of the farm gate price for agricultural commodities. Inside the high rainfall areas of Kenya, milk manufacturing is the main source of earnings for extra than six hundred Thousand families, and manufacturing of sheep, goats and rooster is also promoted with the purpose of alleviating poverty (First Medium Term Plan 2008-2012, p. 79).

This research will be focus on strategies of UNDP and GEF as International Organizations to addressing Improvement of the viability of Agro- Pastoral production system in Kenya, especially in managing land degradation with Sustainable Land Management.

In conducting the research the authors will be using the qualitative research method and according to J. W. Creswell "Qualitative Research is an inquiry process of Understanding based on distinct methodological traditions of inquiry that explore a social or human problem. The research builds a complex holistic pictures, analyzes words, reports detailed views of informants, and conducted the study in natural setting." (Niederhoffer \& Pennebaker, 2009). It uses the project that build by UNDP and GEF events as the foundation or the starter of the research. To answer the research question, the author will use Primary and Secondary data that collection approaches in this research were based on the report of project it will be as follow: Review of primary data sources including national and project based documents with a bearing on project design, implementation and monitoring. In addition, data was also collected from national policies and strategies to implement international conventions and web sites.

\section{Methods}

International organizations serve a variety of functions according to preferences and experts. It collects information, monitor trends, provide services and assistance, provide forums and settles disputes. In other words, each international organization serves a specific role in international affairs based on its interests. International 
organizations exist based on the concept of legal space between state sovereignty and legal obligations created by the commitment of sovereign states with the aim of binding the state to their commitments (Shern et al., 2014).

The legal space refers to agreements that come from countries that allow the involvement of international organizations to work and Ian Hurd has explained that the international organizations "were formed by international law as independent entities separate from the countries that made them their founders and members (Hurd, 2014).

International Organization work with countries as members to pursue common goals and objectives. To protect cooperation between IO's and state or non-state actors, often regulate rules or agreements for behavior and activities in the international system.

Martha Finnermore in her book National of Interest in International Society has argued that the international organizations are an important component of the social structure that is redefining state preferences. She believes that international norms are being distributed by the existence of international organizations working in countries, that international norms promoted by IOs can deceptively influencing national guidelines by encouraging countries to adopt international norm. In addition, her study revealed that international organizations and countries can work together to achieve common goals (Finnemore, 1996).

These two perspectives will conceptualize international organizations assisting the author of this Research to analyze the process of state change in adopting norms distributed by UNDP by dealing with the problem of Environmental Issues in this case of land degradation. In addition to it also determines the function served by UNDP as an international organization expertise in building and protecting the environment issues.

\section{Results And Discussion}

Government of Kenya Plan through the country vision and International Organization Project Sustainable Land Management - The UNDP initiative has had a significant impact on aspects of development based on freedom from desire and freedom from fear, where human security is defined as security and protection as well as protection from chronic conditions such as hunger, disease and oppression. Building on the UNDP initiative, the disruptive habits of everyday life divides life emergencies into seven interconnected security domains: economic, food, health, environmental, personal, social and political (Smith, Jacques-Carroll, Walker, Sirotkin, \& Murphy, 2012). Due to the project of UNDP and GEF that used The Sustainable Land Management it can be a solution for the case of land degradation in Kenya, The main objective of Sustainable Land Management (SLM) is to maintain the functions and services of ecosystems and also support human welfare. SLM has great potential and ability to adapt to local contexts and can preserve and enhance ecosystem services in all land use systems.The UN in 1992 on Rio Earth Summit was define the Sustainable Land Management as "The use of land resources, including soils, water, animals and plants, for the production of goods to meet changing human needs, while simultaneously ensuring the long-term productive potential of these resources and the 
maintenance of their environmental functions" (United Nations Conference on Environment \& Development, 1992).

According to Strategies for Sustainable Land Management in East African Highlands by John Pender, Frank Piace and Simeon Ehul, their bring up the issue of Land Degradation that densely populated in highlands of East Africa and else where on the Africa continent. Highlands is region that support the majority of rural populations with the complex problems of serve poverty, Low income productivity and poor natural resources management. Beside that what happens in the highlands region may provide pertinent insights for what will happen as population density increases and agriculture intensifies in the further of Africa. The Argo climatic conditions from de ASALs also brings the issue for the market opportunities, however to achieve more sustainable and productive land management is urgent need the requiring policy, institutional and also the technological strategies that are well and focus to the targeted the various landscapes variant of biophysical and socio-economic context in the east Africa Highland (Pender, Place, \& Ehui). Then the another relevant idea from Elliot Fratkin in East Africa Pastoralism in Transition: Maasai, Boran and Redille Cases, that analyze the problems faced by the pastoralist societies in East Africa and understand how they have managed to withstand issues such as over population, loss of lands to urban development, droughts and famines. Focus was given to how three societies in particular, Massai, Boran, and Rendille showed resilience by adapting a variety of social and economic strategies. Elliot Fratkin argue how some of these hurdles came about. He attributes over population to high fertility rates and lesser cases of child mortality. Over population has had direct consequences since pastoralist in East Africa have limited resources which cannot cater to the needs of a growing population and another problems that are include commoditization, sedentarization and urban migration (Franklin, Maudie, \& Lavigne, 2001).

Fratkin, continues to explore three examples from Kenya the Massai, Boran and Rendille demonstrating how the mentioned problems are unfolding. He talks about the appropriation of Massai land, the effects of civil war and outliving droughts and developments. The study is concluded by pointing out that among the Massai, loss of land and expansion of commercial activity has led to an ever growing divide amongst the rich and poor nut they have showed resilience by speeding up their agro-pastoralism and commoditization of their economy. Studies on Rendille illustrated that settlement of pastoralists have led to a decline in women and children's health and nutrition however on a positive side, the availability of farms and towns have provided a release for overpopulation (Franklin et al., 2001). UNDP-GEF Strategies in Improving Viability on Argo Pastoral Productivity through SLM. Based on the Project on Mainstreaming Sustainable Land Management in Agro-pastoral Production Systems of Kenya the UNDP divided the Strategies into 3 ways that will be used to address the goals.

The first strategies is Knowledge based land use planning forms the basis for improving drylands sustainable economic development, According to (Castrén et al., 2010). Under this strategies UNDP will build on the PPG studies to deepen 
understanding of the natural potential of the land through landscape productivity and functionality analysis, Land managers and resource users will be provided with skills and support system to apply a wide-range of SLM practices however It will update the land capability maps and land use plans (in a GIS system), update range condition and determine current livestock carrying capacities, and potential for dryland cropping. In addition, guidelines for integrated land use planning at the landscape/ village level will be developed, based on existing good practice and The guidelines will outline the key steps and process for stakeholders (community members, Village Councils, Village Development Boards, scientists, government representatives, and private businesses if applicable) to come together and discuss how to manage lands to increase individual household productivity in tandem with improvements at the landscape level, for the benefit of current and future generations and to ensure ecological sustainability of lands and resources, The community will have the opportunity to engage in intensive training and experimentation to integrate SLM knowledge with agricultural innovation using the Farmer Field School (FFS) method. FFS training is conducted both at the field level, where the group will conduct field trials and experiments, and at the landscape level, where the group will provide community leadership for extensive ecosystem interventions and testing of new natural resource management mechanisms. Support is provided to mobilize community-based natural resource management in selected landscapes and community areas using Land care and integrated ecosystem approaches instead of traditional sectoral interventions.

The Second Strategies is Diversification and increased access to finance for SLM based on (Castrén et al., 2010). Diversification of livelihoods is a strongly established and increasingly popular strategy for managing risk and increasing monetary incomes moreover, Under this strategies UNDP will facilitate further community engagement with the markets by encouraging public private partnerships in marketing of livestock and livestock products as well as facilitating access to markets for specialized products such as honey, high value crops etc. Livestock traders in the ASAL engage in different types of social networks to better confront the risks and uncertainties imposed by poor dissemination of market information, a weak market infrastructure, insecurity, and highly volatile livestock prices. Although trader networks span the entire marketing chain from production centers in the rangelands to the main terminal markets in Nairobi, many of the network interactions are conducted on a highly personal and individualized basis, and are riddled with market inefficiencies. The project will seek to remove these market inefficiencies and to improve the returns in value chain of the livestock trade, leading to better livestock prices for producers, increased and competitive supply of food items and other supplies in the markets, and increased revenues for the local councils.

Adopting the idea by Oliver Kiptoo Kirui and Alisher Mirzabaev in Economic of Land Degradation in Eastern Africa, their general overview regarding the state and extent of Land Degradation in East Africa, is to identify the Land Degradation hotspot in the region, and also the productivity and poverty impacts of Land Degradation in the 
region. There is has interlinkages between Land and Poverty that can be strong in the rural areas of low income countries where the livelihood predominately depend on Agriculture. Beside that lack of information and knowledge is considered as one of the major obstacle to reducing land degradation improving the Agriculture Productivity and facilitating SLM among smallholder farmers, beside that Oliver Kipto and Alisher conclude that causes of Land Degradation are include Socioeconomic and Institutional factors, such as Land Tenur security, Poverty, Population density and weak policy and also regulation environment in Agriculture also Environmental sector, Moreover SLM policies seeking is need it to address the drivers and Land Degradation Support (Kirui \& Mirzabaev, 2014).

The Third Strategies is The policy, regulatory and institutional arrangement support mainstreaming of sustainable land management in the agro-pastoral production system, as part of these strategies, that stated in (Castrén et al., 2010) that UNDP has strengthened its political and institutional framework to support ASAL's sustainable land management, strengthened regional participation in policy review and implementation, and traditional institutions. Strengthen local resource management and support cross-sectoral SLM decision-making by revitalizing beside that the implementation is piloting new rules and regulations for charcoal. The government started the political reform process in 2004, starting with the ASAL document. This policy is progressive, but still not well understood by most shepherds and shepherds of agricultural technology. Moreover, the institutional framework for implementation is still weak. This project will contribute to policy reform by raising awareness of the new policy to land users and strengthening the institutional policy framework at the local level for implementation. Therefore, this project facilitates joint reviews of current land use policies in ASAL, agriculture, water, land use, and policy development processes, and collects community contributions to land use policy reviews and changes. 


\section{Conclusions}

1. Knowledge base for landscape based land use planning in place

Under this goals result farmer groups organised into Farmer/Pastoral Field Schools (FFS) were trained in land use planning and in improved farming practices such as crop rotation, inter-cropping and the use of manure and fertilizers. Degraded lands were also rehabilitated through reseeding. The project also engaged the Kenya Agriculture, Livestock and Research Organisation (KALRO) to conduct participatory research in soils management techniques aimed at improving soil fertility. KALRO also led the process of studying the characteristics of the soils at all the sites the project was implemented. The farm plan level information gathered through this activity would prove invaluable in advising farmers on what crops they could grow as well as what they needed to do to improve soil fertility. This approach was an improvement on previous soil surveys in Kenya which were conducted at district level and were of limited utility to the local farmer.

The results of the participatory research on land and water resources dynamics in the pasture lands and arable lands of ASALs have increased the understanding of the basis for SLM among involved community groups. It is therefore expected that these community groups will be able to mainstream SLM in their future agricultural activities.

2. Viability of the agro-pastoralism production system increased through diversification and increased access to finance for SLM

Under this goals the SLM project has introduced interventions aimed at increasing the value of the agro-pastoral production systems through the introduction of improved livestock breeds and crops that are best suited to these environments. Further the project has introduced the producer groups in ASALs to financing entities like Kenya Commercial Bank and Equity Bank which have provided financial literacy training to enable community members to access financing for their activities.

The result shown that Livestock trade improved While the SLM project has done a lot to improve the quality of livestock in the ASALs through the introduction of improved breeds such as Galla goats and dairy goats it is too early to tell whether these improved varieties will have the impact that is intended. There is some improvement in the quantities of milk produced at the individual farmer level but the increases are insignificant. Further, market linkages which would enable the farmers to sell their stock at higher prices are still to be developed even though there are report of livestock prices having gone up by $30 \%$, and milk and meat production have gone up by $50 \%$ since the introduction of improved breeds.

The SLM Project is beginning to show clear evidence of the potential the ASALs have to support successful and viable land based economic activities, For this potential to be realised it will be necessary to generate a clear understanding of the ecological dynamics at play in these landscapes. Land resource users in the regions also need to have the capacity to exploit the resources in the area in a 
sustainable manner. The SLM project has ably demonstrated what needs to be done in these landscapes for the residents to be able to support viable community livelihoods.

3. The policy, regulatory and institutional arrangement support mainstreaming of sustainable land management in the agro-pastoral production system:

Policies relevant to SLM reviewed in participatory processes and recommendations for mainstreaming SLM generated, the development context in every country changes over time and might require the creation of new institutions and policies to facilitate specific development planning initiatives. Recognising that there had been changes in the policy and institutional framework that guided land use and land management in Kenya, the SLM project commissioned a study to review the various policies that influence land management with a view to recommending appropriate policy directions for advancing this process in the ASALs of Kenya.

As a result of the review, SLM has been mainstreamed into the new National Livestock Policy, the draft National Camel Policy and the National Climate Change Policy. The policy and institutional review highlighted the need, among other processes, for the following actions: the development of legal guidelines for the institutionalisation of SLM at national and County level, the need for the development of land use guidelines for the various agro-ecological regions of the country, the need to enforce policies on soil and water conservation in the ASAL regions of the country, the need to take stock of the land tenure regimes in the country given the close relationship that exists between land tenure and sustainable land management, the need to ensure that sustainable land management was mainstreamed into the development planning processes of the newly devolved government system, the need to ensure the mainstreaming of SLM into the National Livestock Policy and the draft National Camel Development Policy, the need to mainstream the implications of climate change into national and local development initiatives. 


\section{BIBLIOGRAFI}

Bartelmus, Peter. (2013). The future we want: Green growth or sustainable development? Environmental Development, 7, 165-170. Google Scholar

Brabham, Daren C. (2008). Crowdsourcing as a model for problem solving: An introduction and cases. Convergence, 14(1), 75-90. Google Scholar

Busch, H. J., Eichwede, F., Födisch, M., Taccone, F. S., Wöbker, G., Schwab, T., Hopf, H. B., Tonner, P., Hachimi-Idrissi, S., \& Martens, Paul. (2010). Safety and feasibility of nasopharyngeal evaporative cooling in the emergency department setting in survivors of cardiac arrest. Resuscitation, 81(8), 943-949. Google Scholar

Castrén, Maaret, Nordberg, Per, Svensson, Leif, Taccone, Fabio, Vincent, Jean Louise, Desruelles, Didier, Eichwede, Frank, Mols, Pierre, Schwab, Tilmann, \& Vergnion, Michel. (2010). Intra-arrest transnasal evaporative cooling: a randomized, prehospital, multicenter study (PRINCE: Pre-ROSC IntraNasal Cooling Effectiveness). Circulation, 122(7), 729-736. Google Scholar

Duffield, Mark, \& Waddell, Nicholas. (2006). Securing humans in a dangerous world. International Politics, 43(1), 1-23. Google Scholar

Finnemore, Martha. (1996). Norms, culture, and world politics: insights from sociology's institutionalism. International Organization, 50(2), 325-347. Google Scholar

Franklin, S. E., Maudie, A. J., \& Lavigne, M. B. (2001). Using spatial co-occurrence texture to increase forest structure and species composition classification accuracy. Photogrammetric Engineering and Remote Sensing, 67(7), 849-856. Google Scholar

Gok, Cem, \& Aytas, Sule. (2009). Biosorption of uranium (VI) from aqueous solution using calcium alginate beads. Journal of Hazardous Materials, 168(1), 369-375. Google Scholar

Kirui, Oliver Kiptoo, \& Mirzabaev, Alisher. (2014). Economics of land degradation in Eastern Africa. ZEF working paper series. Google Scholar

Mcsweeney, Carol, New, Mark, Lizcano, G., \& Lu, X. (2010). The UNDP Climate Change Country Profiles: Improving the accessibility of observed and projected climate information for studies of climate change in developing countries. Bulletin of the American Meteorological Society, 91(2), 157-166. Google Scholar

Moschella, Manuela. (2010). Governing risk: The IMF and global financial crises. Springer. Google Scholar 
Mulinge, Munyae, \& Mueller, Charles W. (1998). Employee job satisfaction in developing countries: The case of Kenya. World Development, 26(12), 21812199. Google Scholar

Niederhoffer, Kate G., \& Pennebaker, James W. (2009). Sharing one's story: On the benefits of writing or talking about emotional experience. Google Scholar

Plaizier, J. C. B. (1993). Validation of the FAO/IAEA RIA kit for the measurement of progesterone in skim milk and blood plasma. Improving the Productivity of Indigenous African Livestock, IAEA-TECDOC-708, IAEA, Vienna, 151-156. Google Scholar

Shern, Jack F., Chen, Li, Chmielecki, Juliann, Wei, Jun S., Patidar, Rajesh, Rosenberg, Mara, Ambrogio, Lauren, Auclair, Daniel, Wang, Jianjun, \& Song, Young K. (2014). Comprehensive genomic analysis of rhabdomyosarcoma reveals a landscape of alterations affecting a common genetic axis in fusion-positive and fusion-negative tumors. Cancer Discovery, 4(2), 216-231. Google Scholar

Smith, Emily A., Jacques-Carroll, Lisa, Walker, Tanja Y., Sirotkin, Barry, \& Murphy, Trudy V. (2012). The national perinatal hepatitis B prevention program, 19942008. Pediatrics, 129(4), 609-616. Google Scholar

Yildiz, Mete. (2007). E-government research: Reviewing the literature, limitations, and ways forward. Government Information Quarterly, 24(3), 646-665. Google Scholar

\section{Copyright holder:}

Recindy Gilang Melati (2022)

First publication right:

Syntax Literate: Jurnal Ilmiah Indonesia

This article is licensed under: 